\title{
Uncontrolled Delayed Intraocular Pressure
}

National Cancer Institute

\section{Source}

National Cancer Institute. Uncontrolled Delayed Intraocular Pressure. NCI Thesaurus.

Code $C 50786$.

Changes in the fluid pressure inside the eye. 